Louisiana State University

LSU Digital Commons

Faculty Publications

Department of Biological Sciences

$1-1-2014$

\title{
Spatiotemporal expression of TRPM4 in the mouse cochlea
}

\author{
Mayumi Sakuraba \\ Juntendo University Graduate School of Medicine \\ Junko Murata \\ Juntendo University Graduate School of Medicine \\ Ryoichi Teruyama \\ Louisiana State University \\ Kazusaku Kamiya \\ Juntendo University Graduate School of Medicine \\ Junji Yamaguchi \\ Juntendo University Graduate School of Medicine
}

See next page for additional authors

Follow this and additional works at: https://digitalcommons.Isu.edu/biosci_pubs

\section{Recommended Citation}

Sakuraba, M., Murata, J., Teruyama, R., Kamiya, K., Yamaguchi, J., Okano, H., Uchiyama, Y., \& Ikeda, K. (2014). Spatiotemporal expression of TRPM4 in the mouse cochlea. Journal of Neuroscience Research, 92 (10), 1409-1418. https://doi.org/10.1002/jnr.23410

This Article is brought to you for free and open access by the Department of Biological Sciences at LSU Digital Commons. It has been accepted for inclusion in Faculty Publications by an authorized administrator of LSU Digital Commons. For more information, please contact ir@lsu.edu. 


\section{Authors}

Mayumi Sakuraba, Junko Murata, Ryoichi Teruyama, Kazusaku Kamiya, Junji Yamaguchi, Hideyuki Okano, Yasuo Uchiyama, and Katsuhisa Ikeda 


\title{
Spatiotemporal Expression of TRPM4 in the Mouse Cochlea
}

\author{
Mayumi Sakuraba, ${ }^{1}$ Junko Murata,${ }^{1} \star$ Ryoichi Teruyama,${ }^{2}$ Kazusaku Kamiya, ${ }^{1}$ \\ Junji Yamaguchi, ${ }^{3}$ Hideyuki Okano, ${ }^{4}$ Yasuo Uchiyama, ${ }^{3}$ and Katsuhisa Ikeda ${ }^{1}$ \\ ${ }^{1}$ Department of Otorhinolaryngology, Juntendo University Graduate School of Medicine, Tokyo, Japan \\ ${ }^{2}$ Department of Biological Sciences, Louisiana State University, Baton Rouge, Lousiana \\ ${ }^{3}$ Department of Cellular and Molecular Neuropathology, Juntendo University Graduate School of \\ Medicine, Tokyo, Japan \\ ${ }^{4}$ Department of Physiology, Keio University School of Medicine, Tokyo, Japan
}

The present study was conducted to elucidate the presence of the transient receptor potential cation channel subfamily M member 4, TRPM4, in the mouse inner ear. TRPM4 immunoreactivity (IR) was found in the cell body of inner hair cells (IHCs) in the organ of Corti in the apical side of marginal cells of the stria vascularis, in the apical portion of the dark cells of the vestibule, and in a subset of the type II neurons in the spiral ganglion. Subsequently, changes in the distribution and expression of TRPM4 in the inner ear during embryonic and postnatal developments were also evaluated. Immunohistochemical localization demonstrated that the emergence of the TRPM4$\mathrm{IR}$ in IHCs occurs shortly before the onset of hearing, whereas that in the marginal cells happens earlier, at the time of birth, coinciding with the onset of endolymph formation. Furthermore, semiquantitative real-time PCR assay showed that expressions of TRPM4 in the organ of Corti and in the stria vascularis increased dramatically at the onset of hearing. Because TRPM4 is a $\mathrm{Ca}^{2+}$-activated monovalent-selective cation channel, these findings imply that TRPM4 contributes to potassium ion transport, essential for the signal transduction in IHCs and the formation of endolymph by marginal cells. () 2014 Wiley Periodicals, Inc.

Key words: TRP channel; endolymph; inner hair cell; stria vascularis; marginal cell

When acoustic stimuli reach the cochlea as fluid pressure waves, the basilar membrane underlying the organ of Corti is put into motion. This vibration elicits the deflection of stereocillia, cytoplasmic extensions of the hair cells (HCs), and causes opening of mechanoelectrical transduction channels to cations in the endolymph, a fluid compartment high in potassium concentration (Fig. 1). Because the cochlear endolymph is high in $\mathrm{K}^{+}(\sim 150 \mathrm{mM})$ and low in $\mathrm{Na}^{+}(\sim 2 \mathrm{mM})$ and $\mathrm{Ca}^{2+}(\sim 20 \mu \mathrm{M})$ with positive endocochlear potential of $+80 \mathrm{mV}$ (Von Bekesy, 1952), the process allows $\mathrm{K}^{+}$to flow into HCs to induce their electrical excitation (Hudspeth and Corey, 1977; Hudspeth, 1989). Then $\mathrm{K}^{+}$exits across their basolateral membranes through $\mathrm{K}^{+}$channels and reaches the lateral wall of the cochlea (Fig. 1A; Zdebik et al., 2009).
The lateral wall of the cochlea is formed by the spiral ligament and the stria vascularis. The connective tissue of the spiral ligament contains five types of fibrocytes (type I-V). The stria vascularis is an epithelial tissue and is composed of marginal, intermediate, and basal cells (Fig. 1A). The basal and intermediate cells and nearby fibrocytes are connected tightly, forming one functional layer (the basal-intermediate cell layer; Cohen-Salmon et al., 2002; Nin et al., 2008), and the marginal cells constitute a monolayer. The extracellular space between the basalintermediate cell and the marginal cell layers is called the intrastrial space (IS). After reaching the lateral wall of the cochlea, $\mathrm{K}^{+}$is transported from perilymph to the basalintermediate cell layer of the stria vascularis and subsequently moved into the IS (Hibino et al., 2010). $\mathrm{K}^{+}$is taken up from the IS into the marginal cells (Kerr et al., 1982; Wangemann et al., 1995) and released into the endolymph through KCNQ1/KCNE1 heterometric channels in the apical membrane of marginal cells (Sakagami et al., 1991; Marcus and Shen, 1994).

The cloning of the transient receptor potential (TRP) channel protein in 1989 (Montell and Rubin, 1989) led to the discovery of a large family of $\mathrm{Ca}^{2+}$-activated nonselective cation channels that were molecularly unidentified previously. Among 29 identified mammalian TRP channels, two of the melastatin-related subfamily, TRPM4 and TRPM5 (TRP melastin-related subfamily members 4 and 5), are the only monovalent-selective

Additional Supporting Information may be found in the online version of this article.

Contract grant sponsor: JSPS, contract grant number: 23592496 (to J.M.); Contract grant sponsor: Research Institute for Diseases of Old Age, Institute for Environmental and Gender-Specific Medicine, of Juntendo University (to J.M.)

^Correspondence to: Junko Murata, Department of Otorhinolaryngology, Juntendo University Graduate School of Medicine, 2-1-1, Hongo, Bunkyo-ku, Tokyo 113-8421 Japan. E-mail: jmurata@juntendo.ac.jp

Received 23 September 2013; Revised 26 February 2014; Accepted 14 April 2014

Published online 20 May 2014 in Wiley Online Library (wileyonlinelibrary.com). DOI: 10.1002/jnr.23410 


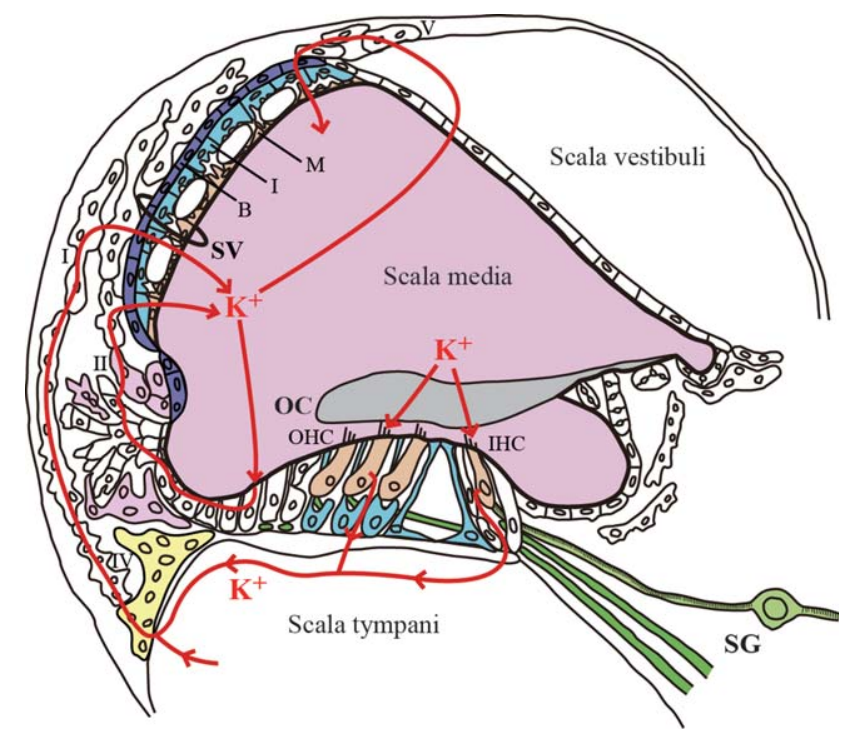

Fig. 1. Schematic drawing of the cochlear duct of mice. A crosssection of the cochlear duct was schematically drawn to indicate the flow of $\mathrm{K}^{+}$. The scala media are filled with endolymph, an unusual extracellular fluid (high in $\mathrm{K}^{+}$and low in $\mathrm{Na}^{+}$and $\mathrm{Ca}^{2+}$ ), resulting in a positive endocochlear potential of $+80 \mathrm{mV}$. The lateral cochlear wall is formed by two components: 1) spiral ligaments, the connective tissue containing five types of fibrocytes (type $\mathrm{I}-\mathrm{V}$, indicated as $\mathrm{I}-\mathrm{V}$ ), and 2) the stria vascularis (SV), which is epithelial tissue composed of marginal (M), intermediate (I), and basal (B) cells. The organ of Corti (OC) represents the sensory epithelium of the cochlea and contains sensory inner hair cells (IHCs) and outer hair cells (OHCs) with associated supporting cells. Sound-induced mechanical vibration moves the basilar membrane of the OC. The afferent and efferent neurons from the spiral ganglion (SG) innervate the IHCs and OHCs.

cation channels (Guinamard et al., 2010). TRPM4 and TRPM5 both are activated by increasing intracellular $\mathrm{Ca}^{2+}$ (Launay et al., 2002; Nilius et al., 2004; Zhang et al., 2007). TRPM4 is activated when internal ATP is decreased, whereas TRPM5 is not ATP sensitive (Nilius et al., 2005; Ullrich et al., 2005). TRPM4 was cloned as a 1,214-amino-acid molecule, encoded by a gene located on human chromosome 19 (Launay et al., 2002). TRPM4 is expressed and functions in a wide variety of cell types, including inspiratory neurons (Mironov, 2008), cardiomyocytes (Guinamard et al., 2004), and cerebral atrial myocytes (Earley et al., 2004). TRPM4 is also found in epithelial systems, including renal tubules (Chraibi et al., 1994; Guinamard et al., 2012).

Early investigations of the inner ear indicated the presence of TRPM4 transcripts (Cuajungco et al., 2007) and TRPM4 protein in the murine organ of Corti. Moderate TRPM4 immunoreactivity (IR) was detected in cochlear supporting cells, and the only faint TRPM4-IR was observed in stria vascularis, vestibular HCs, spiral and vestibular ganglion cells (Takumida et al., 2009). The present study was carried out to characterize further the expression pattern of TRPM4 during development.

\section{MATERIALS AND METHODS}

\section{Animals}

C57BL/6J mice were obtained from SRL (Shizuoka, Japan) for this study. Embryonic day 0.5 (E0.5) was defined as noon of the day on which a vaginal plug was observed. The day of birth was designated as postnatal day $0(\mathrm{P} 0)$. All experimental protocols were approved by the Animal Research Committee at the Juntendo University School of Medicine (approval numbers 240107, 250227) and were conducted in accordance with the NIH Guide for the care and use of laboratory animals.

\section{Antibodies}

A polyclonal anti-TRPM4 antibody was generated in rabbit by immunizing with a 15 -amino-acid synthetic peptide corresponding to amino acids 60-74 (NH2-TEWNSDEHTTEKPTDC-COOH) of the amino-terminal tail of the rat TRPM4, with an added carboxyl-terminal cysteine (Teruyama et al., 2011). The antiserum was affinity purified on a column made with the synthetic peptides to produce the anti-TRPM4 rabbit polyclonal antibody $(77.5 \mu \mathrm{g} / \mathrm{ml}$; Teruyama et al., 2011). This antibody recognizes a predominant band of $\sim 134 \mathrm{kDa}$ corresponding to the predicted molecular weight of TRPM4 on an immunoblot run by using a membrane fraction of MCF7 cells (Supp. Info. Fig. 1). The anti-TRPM4 antibody was used at 1:1,000. The other primary antibodies (and their dilutions) used were rabbit polyclonal antimyosin VI antibody (1:300; Proteus Biosciences, Ramona, CA), rat monoclonal antineurofilament $\mathrm{H}$ antibody (1:500; EMD Millipore, Billerica, MA), and mouse monoclonal anti- $\beta$-tubulin class III antibody (TUJ1, 1:100; EMD Millipore). The characterization of these commercial primary antibodies by Western blot is described in each datasheet.

\section{Immunohistochemistry}

Adult mice and pups were deeply anesthetized with pentobarbital. Embryos were removed from deeply anesthetized mothers by cesarean section and cooled on ice. Adult mice, pups, and embryos were perfused through the left ventricle using $4 \%$ paraformaldehyde in $0.1 \mathrm{M}$ phosphate buffer $(\mathrm{PB})$, $\mathrm{pH}$ 7.4. The temporal bones were dissected and postfixed overnight at $4^{\circ} \mathrm{C}$. The temporal bones collected from mice older than 7 days were further decalcified in 5\% EDTA in $0.1 \mathrm{M} \mathrm{PB}$ for 1 week. The specimens were cryoprotected in 30\% sucrose in $0.1 \mathrm{M}$ phosphate saline buffer overnight at $4^{\circ} \mathrm{C}$, then embedded and frozen in Tissue-Tek OCT compound 4583 (Sakura Fine Technical, Tokyo, Japan). The cochleae were sectioned at $8 \mu \mathrm{m}$ with a cryostat and affixed to MAS-coated glass slides (Matsunami Glass, Osaka, Japan). At least three tissue sections were collected from a single cochlea. Cochleae were collected from three mice for each developmental stage of E15.5, P0, P7, 2-week-old, and 4-week-old mice. For immunohistochemistry of TRPM4, antigen retrieval was accomplished by immersing the slides in boiled $0.01 \mathrm{~mol} /$ liter citrate buffer, $\mathrm{pH}$ 6.0, for 10 min, followed by three consecutive washes in Tris-buffered saline (TBS), $\mathrm{pH}$ 7.4. The sections were then permeabilized in TBS containing $0.05 \%$ Tween 20 (TBS-T) for $10 \mathrm{~min}$ and treated with $3 \%$ hydrogen peroxide in methanol for $10 \mathrm{~min}$. 
TABLE I. TRPM4 Immunoreactivity During Development of the Mouse Cochlea

\begin{tabular}{|c|c|c|c|c|c|}
\hline & E15.5 & $\mathrm{P} 0$ & P7 & Two weeks old & Four weeks old \\
\hline Inner hair cells & $-\dagger$ & - & ++ & +++ & +++ \\
\hline Marginal cells & $-\dagger$ & ++ & +++ & +++ & +++ \\
\hline IPs, OPs, DCs & $-{ }^{\dagger}$ & - & - & + & + \\
\hline Reisnner's membrane & - & - & ++ & ++ & + \\
\hline SGNs (somas) & - & + & + & $++^{\mathrm{b}}$ & $+^{\mathrm{b}}$ \\
\hline SGNs (fibers) & - & - & + & ++ & + \\
\hline
\end{tabular}

$\star$ IPs, inner pillar cells; OPs, outer pillar cells; DCs, Deiters' cells; SGNs, spiral ganglion neurons.

${ }^{\dagger}$ Not differentiated.

${ }^{\mathrm{b}}$ Type II $\gg$ type I.

Subsequently, the sections were blocked with TNB blocking buffer (PerkinElmer, Waltham, MA) for $30 \mathrm{~min}$ at room temperature. After overnight incubation with the anti-TRPM4 antibody $(1: 1,000$ in $\mathrm{TNB})$ at $4^{\circ} \mathrm{C}$, the sections were incubated in a biotinylated donkey anti-Rabbit $\mathrm{IgG}$ antibody (Jackson Immunoresearch, West Grove, PA) diluted in TNB (1:200) for $1 \mathrm{hr}$ at room temperature. The antibodies were visualized by using the TSA fluorescence system (fluorescein; PerkinElmer) according to the manufacturer's directions. For double immunostaining with TRPM4, either Alexa Fluor 594-conjugated donkey anti-mouse IgG (1:400; Life Technologies, Carlsbad, CA) or donkey anti-rat IgG (1:400; Life Technologies) secondary antibody was used with the biotinylated donkey anti-rabbit IgG antibody described above. The sections were counterstained with DAPI (Life Technologies), washed with TBS, and mounted. All the confocal fluorescence images were obtained with a laser-scanning microscope (TCS-SP5; Leica Microsystems, Buffalo Grove, IL).

Spiral ganglion neurons (SGNs) in the mature cochlea are composed of two neuron types. Type I neurons make up the majority of the SGN and innervate IHCs; smaller type II neurons are localized laterally in the SG and innervate OHCs. Because $\beta$-III-tubulin in the cell body of type II neurons gradually declines during development, whereas that in type I neurons remains unchanged (Barclay et al., 2011), the labelings of $\beta$-III-tubulin and TRPM4 were used together to identify whether type I or type II SGN express TRPM4.

The results of immunohistochemistry were summarized in Table I. The intensity of TRPM4-IR was described as follows: +++ , intensive IR was detected; ++ , IR was definitely detected but it was not so intensive; + , only diffuse IR was detected; -, IR was not detected at all.

\section{Western Blot Analysis of TRPM4}

Cell culture. MCF-7 cells (Soule et al., 1973) were cultured at $37^{\circ} \mathrm{C}$ in $5 \% \mathrm{CO}_{2}$ in Dulbecco's modified Eagle's medium and high glucose (Life Technologies) supplemented with $10 \%(\mathrm{v} / \mathrm{v})$ fetal bovine serum (Life Technologies).

Extraction of membrane protein. The membrane fraction was prepared from cultured MCF-7 cells (Tesfai et al., 2001). A pellet of MCF-7 cells $\left(2 \times 10^{7}\right.$ cells $)$ was suspended in ice-cold extraction buffer $(50 \mathrm{mM}$ Tris/ $\mathrm{HCl}, 1 \mathrm{mM}$ EDTA, 1\% [v/v] ProteoGuard EDTA-free protease inhibitor cocktail, pH 7.5; Clontech Laboratories, Mountain View, CA) and homogenized by using a glass-glass homogenizer. Homog- enates were centrifuged at $8,000 \mathrm{~g}$ for $10 \mathrm{~min}$ at $4^{\circ} \mathrm{C}$ to remove cellular debris. The supernatant was centrifuged at $50,000 \mathrm{~g}$ for $30 \mathrm{~min}$ at $4^{\circ} \mathrm{C}$ to precipitate the membrane fraction. The pellet was resuspended in chilled extraction buffer containing 1\% (v/ v) Triton X-100.

Western blot analysis. Ten micrograms of MCF-7 whole-cell lysate (Abcam, Cambridge, United Kingdom) and $5 \mu \mathrm{g}$ of MCF-7 membrane fraction were respectively solubilized in equal volumes of Laemmli sample buffer containing 5\% 2-mercaptoethanol and incubated at $37^{\circ} \mathrm{C}$ for $1 \mathrm{hr}$ (Drew et al., 2006). SDS/PAGE was performed on Mini-Protean TGX precast gels 4-20\% (Bio-Rad, Berkeley, CA) and transferred electrophoretically to PVDF membrane (Trans-Blot Turbo Transfer Pack, PVDF, $7 \times 8.5 \mathrm{~cm}$; Bio-Rad). The membrane was blocked for $30 \mathrm{~min}$ at room temperature in TBS-T (20 $\mathrm{mM}$ Tris/HCl, $500 \mathrm{mM} \mathrm{NaCl}, 0.1 \%$ [v/v] Tween 20, pH 8.0) with $5 \%(\mathrm{w} / \mathrm{v})$ skimmed-milk powder and incubated with antiTRPM4 antibody $\left(155 \times 10^{-3} \mu \mathrm{g} / \mathrm{ml}\right.$ in TBS-T $)$ overnight at $4^{\circ} \mathrm{C}$. The membrane was washed and then incubated with peroxidase-conjugated secondary antibody (1:5,000 in TBS-T; GE, Fairfield, CT) for $3 \mathrm{hr}$ at room temperature. The sites of antibody-antigen reaction were visualized with enhanced chemiluminescence (SuperSignal West Dura extended duration substrate; ThermoFisher Scientific, Waltham, MA) and scanned by C-DiGit (LI-COR Biosciences, Lincoln, NE).

\section{Semiquantitative Real-Time Reverse Transcriptase-Polymerase Chain Reaction}

Cochleae were dissected from six mice for each developmental stage of E15.5, E17.5, P0, P2, P7, 2 weeks old, and 4 weeks old. The organ of Corti and the lateral wall were carefully dissected from spiral ganglion neurons and other surrounding tissue and saved separately in RNAlater (Life Technologies). Total RNA was homogenized in RLP- $\beta M E$ buffer (Qiagen, Venlo, The Netherlands), then isolated by using an RNeasy micro kit (Qiagen) and quantified by using the NanoDrop 1000 spectrophotometer (ThermoFisher Scientific). The total RNA $(0.2-0.8 \mu \mathrm{g})$ was annealed to random primer and reverse transcribed to cDNA by using the PrimeScript II first strand cDNA synthesis kit (Takara Bio, Shiga, Japan). Semiquantitative real-time reverse transcriptasepolymerase chain reaction (qRT-PCR) for TRPM4 was performed with the TaqMan Fast Advanced Master Mix with the Applied Biosystems 7500 FAST system (Life Technologies). The expression of TRPM4 was normalized by the expression of 
ribosomal protein large $\mathrm{P} 0(R p l p 0)$, to compensate for the variation in the quality of RNA and the amount of cDNA. The RT-PCR for each sample was performed in triplicate. To analyze the RT-PCR results, the average cycle threshold value (Ct) was determined for each reaction. Differences in $\mathrm{Ct}(\Delta \mathrm{Ct})$ between RplpO and TRPM4 were calculated by subtracting the Ct of TRPM4 from the Ct of RplpO. Changes in the expression of TRPM4 during the development relative to its expression in E15.5 were evaluated by subtracting mean $\Delta \mathrm{Ct}$ at each developmental stage from that of E15.5 and expressed as $2 \Delta \mathrm{Ct}$. TaqMan gene expression assays (Life Technologies) used were Rplp0 (Mm00725448_s1) and TRPM4 (Mm00613173_m1).

\section{RESULTS}

\section{TRPM4-IR Was Observed in the Cochlea}

Immunofluorescence microscopy demonstrated several TRPM4-immunoreactive structures in the cochlea from 2-week-old mice. A robust IR was observed in the apical layer of the stria vascularis, in inner hair cells (IHCs) of the organ of Corti, and in a subset of the spiral ganglion cells and the nerve fibers (Fig. 2A). To confirm the specificity of the anti-TRPM4 antibody, we performed an antibody absorption test. The cochlear sections from 4-week-old mice were incubated with the antiTRPM4 antibody $(0.075 \mu \mathrm{g} / \mathrm{ml})$ that were preincubated with its antigen $(60-74 ; 0.1 \mu \mathrm{g} / \mathrm{ml})$. No immunoreactivity was observed in preabsorbed controls (Fig. 2B), whereas staining without preabsorption had a TRPM4-IR distribution similar to that of 2 -week-old mice (Fig. 2C).

\section{TRPM4 Was Distinctly Localized in the Soma of IHCs and in the Apical Side of the Marginal Cells}

In the organ of Corti of 4-week-old mice, a robust TRPM4-IR was localized in IHCs (Fig. 3A). A weak and diffuse TRPM4-IR was also found in outer hair cells (OHCs), inner pillar cells, outer pillar cells, and Deiters' cells (Fig. 3A). To clarify the location of TRPM4 within the IHC, a section near the section used in Figure $3 \mathrm{~A}$ was immunolabeled with the rabbit anti-myosin VI antibody (Fig. 3B). Myosin VI is located throughout the cell body of HCs but is conspicuously concentrated in the pericuticular necklace and basolateral region (Roux et al., 2009). TRPM4-IR was localized throughout the cell body of IHCs (Fig. 3A,B). Double immunofluorescence was also performed to localize of TRPM4 and neurofilament $\mathrm{H}$ (NFH) in the organ of Corti (Fig. 3C-E). TRPM4-IR of IHC was not attributable to nerve fibers that were immunolabeled with the anti-NFH antibody, although a subset of the fibers was immunoreactive for TRPM4 (Fig. 3C-E, white arrowheads). Labeling of cell nuclei with DAPI clearly demonstrated the location of basal cells, intermediate cells, and marginal cells in the stria vascularis (Fig. 3F). TRPM4-IR was concentrated toward the apical membrane of marginal cells.

The details of the distribution of TRPM4 in the spiral ganglion (SG) were further examined in the cochlea of a 4-week-old mouse. Intense TRPM4-IR was observed in smaller spiral ganglion neurons (SGNs) in the lateral

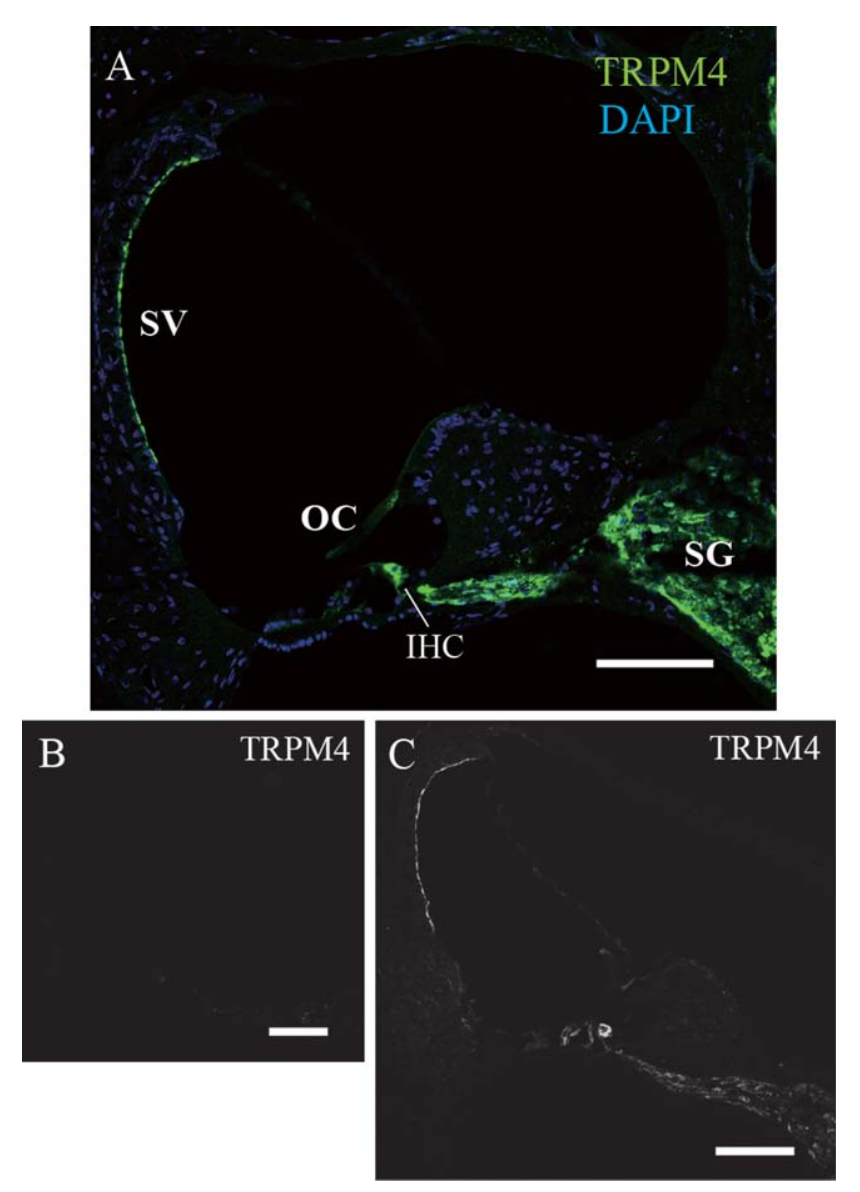

Fig. 2. Immunohistochemical localization of the TRPM4 channel in the mouse cochlea. A: Robust immunoreactivity (IR) of TRPM4 was observed in marginal cells of the stria vascularis, inner hair cells (IHCs) of the organ of Corti, and a part of the spiral ganglion cells and their processes from a 2-week-old mouse. B: The result of an antibody absorption test. A cochlear section preabsorbed with the antigen peptide $(0.1 \mu \mathrm{g} / \mathrm{ml})$ showed no IR. C: TRPM4-IR in the control section of a 4-week-old mouse without preabsorption. The distribution of TRPM4-IR from the cochlea of a 4-week -old mouse was essentially identical to that seen in A. Scale bar $=100 \mu \mathrm{m}$.

portion of the SG (yellow arrowheads in Fig. 3G). Less intense TRPM4-IR was also observed in the larger cell bodies of SGNs located in the rest of the SG (white arrowheads in Fig. 3G,I). The smaller cells that had intense TRPM4-IR (yellow arrowheads in Fig. 3G,I) were nearly immunonegative for $\beta$-III-tubulin (Fig. 3H,I), putative type II SGNs. In contrast, the larger cells that were strongly immunoreactive for $\beta$-III-tubulin, putative type I SGNs (white arrowheads in Fig. 3H,I), were only weakly immunoreactive for TRPM4 (Fig. 3G,I).

\section{TRPM4-IR Is Concentrated Toward the Apical Membrane of Dark Cells in the Vestibular Labyrinth}

Immunohistochemical localization of TRPM4 was also examined in the lateral semicircular canal of the 

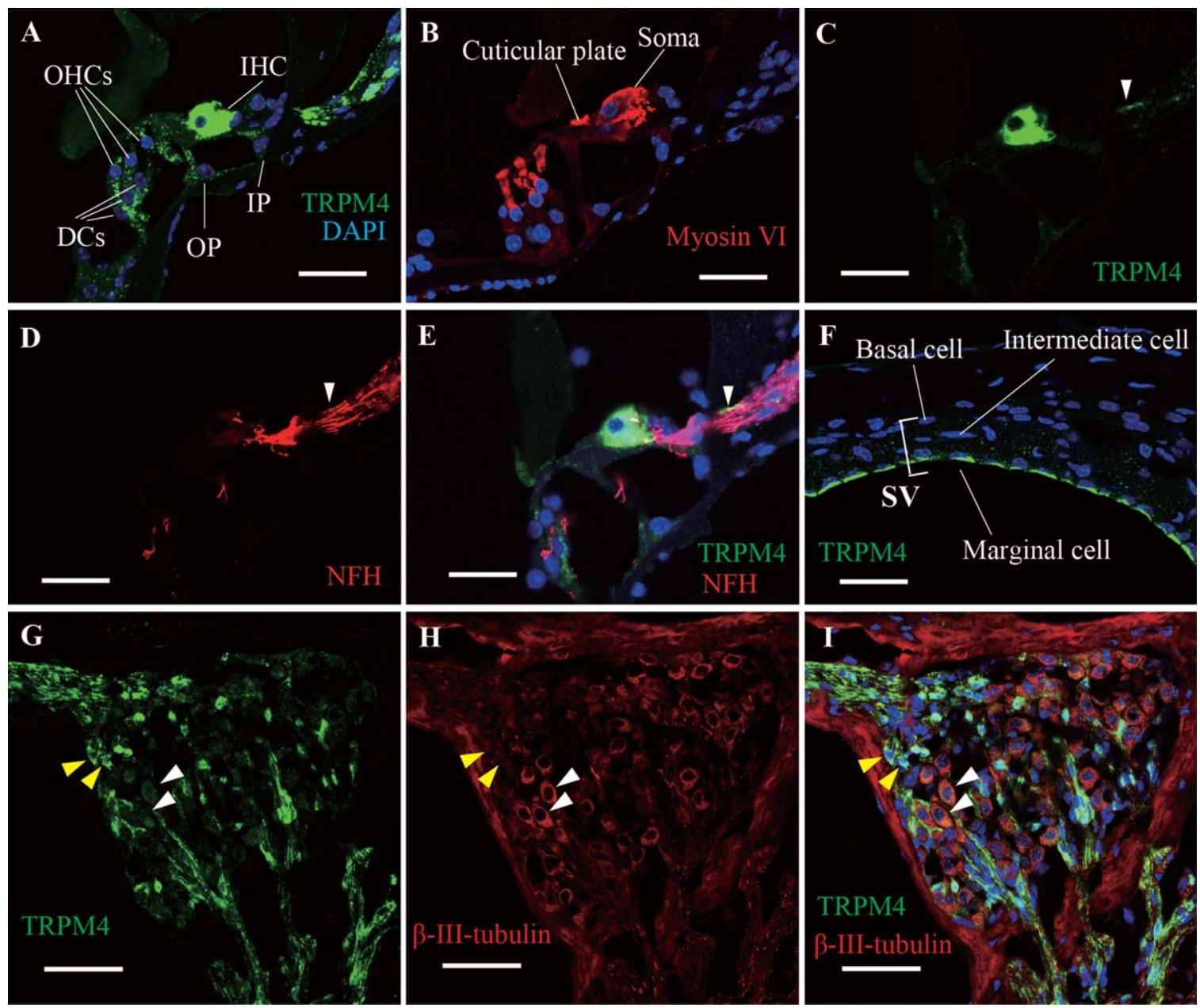

Fig. 3. Localization of the TRPM4 channel in the soma of inner hair cells (IHCs) and in the apical membrane of the strial marginal cells. A: A robust TRPM4-IR (green) was localized to IHCs, whereas diffuse IR was found in outer hair cells (OHCs), in the inner pillar (IP), in the outer pillar (OP), and in Deiters' cells (DC) in the organ of Corti from the cochlear turn of a 4-week-old mouse. Nuclei were counterstained by DAPI (blue). B: A section adjacent to that used in A was immunostained for myosin VI (red). Myosin VI is located the hair cells, except in the hair bundle; however, myosin VI is particularly concentrated in the cuticular plate and the pericuticular necklace region. This indicates that TRPM4-IR was solely in the soma under the circumferential band, which has access to the perilymph but not to the endolymph. C: A section adjacent to B was immunostained for TRPM4 (green). D: The same section used in $\mathrm{C}$ also was immunostained for neurofilament $\mathrm{H}$ (red: NFH). E: Merged image of C and D showing that TRPM4-IR of IHCs did not originate from the

vestibule from 2-week-old mice. Each semicircular canal contains a sensory epithelium, the crista ampullaris, which is a thickened epithelial ridge oriented perpendicular to the long axis of the duct. The crista ampullaris is surrounded by a nonsensory transitional epithelium (Fig. 4A), which continues to the dark cell's regions. Intense TRPM4-IR was found in HCs of the crista ampullaris and dark cells in the lateral semicircular canal. However, innervating axons, although a subset of the axons did express TRPM4 (arrowhead). F: A section including the stria vascularis from a 4week-old mouse was immunostained for TRPM4 (green). The counterstaining of the cell nuclei with DAPI (blue) allows the nuclei of basal cells, intermediate cells, and marginal cells to be distinguished. The results clearly show that TRPM4-IR is localized in the apical surface of the marginal cells. G,H: A section of the spiral ganglion from a 4-week-old mouse was immunostained for TRPM4 (green; $\mathrm{G}$ ) and $\beta$-III-tubulin (red; H). I: Merged image of $\mathrm{G}$ and $\mathrm{H}$. A robust TRPM4-IR was observed in small, $\beta$-III-tubulin-immunonegative type II neurons (yellow arrowheads) that innervate OHCs. In contrast, only faint TRPM4-IR was observed in large $\beta$-III-tubulinimmunopositive type I neurons that innervate IHCs. Note the relatively reddish cell body with small yellow granules (white arrowheads). Scale bars $=30 \mu \mathrm{m}$ in A-F; $50 \mu \mathrm{m}$ in $\mathrm{G}-\mathrm{I}$.

no prominent TRPM4-IR was observed in the transitional cells (Fig. 4A, Supp. Info. Fig. 2A,B). Furthermore, a higher power image demonstrated that TRPM4-IR is concentrated on the apical side within dark cells, although some weak IR was also dispersed in the rest of the cell body (Fig. 4B). A section containing the crista ampullaris of the posterior semicircular canal was double labeled with the TRPM4 (Fig. 4C, green) and NFH (Fig. 4D, 

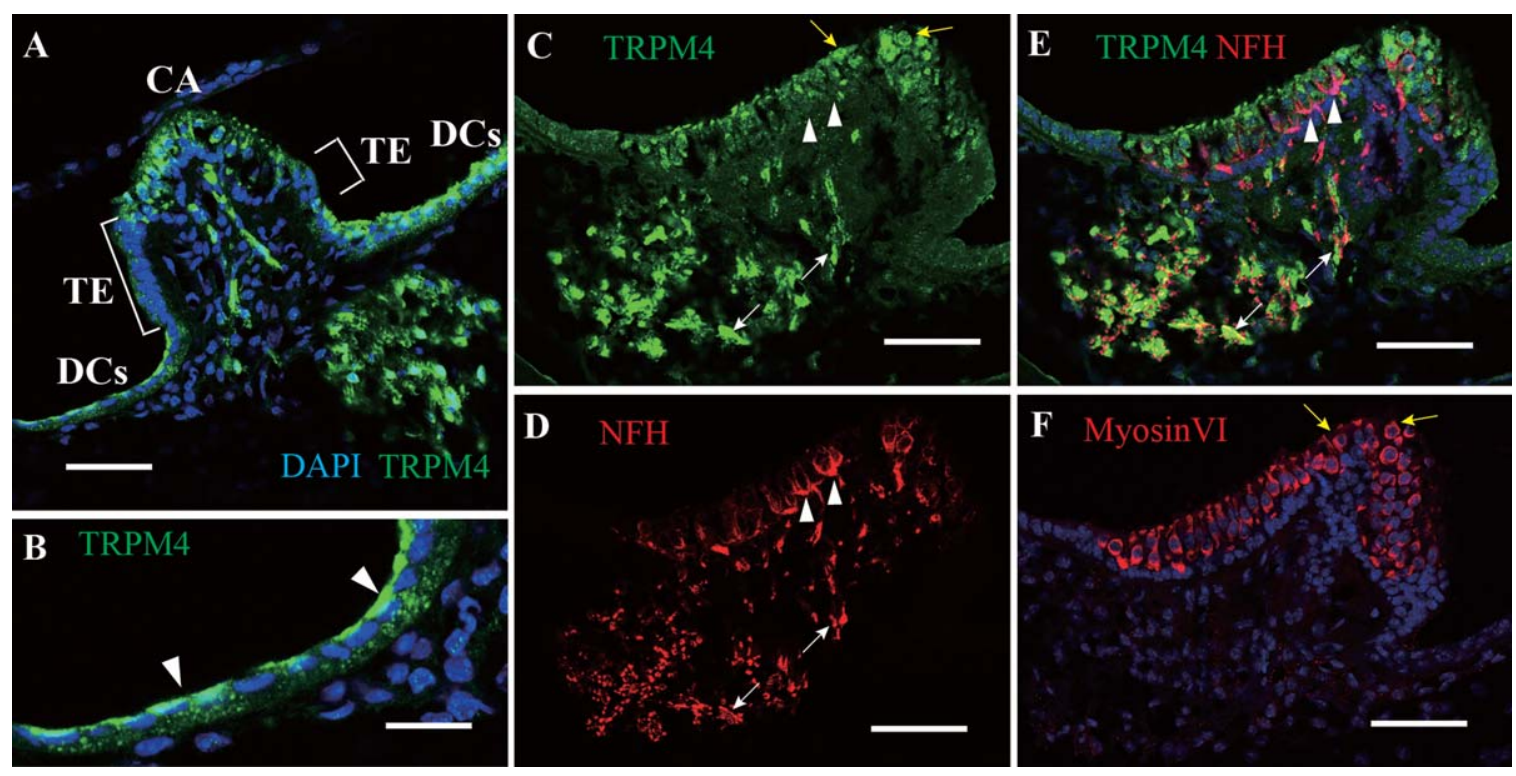

Fig. 4. TRPM4-IR was observed in hair cells (HCs) and in the apical side of dark cells but not in the transitional cells of the vestibular epithelium. A: The vestibular labyrinth contains a sacculus, a utriculus, and three semicircular canals filled with endolymph. The crista ampullaris (CA) is the sensory epithelium of the semicircular canals. The transitional epithelium (TE) that surrounds the crista ampullaris continues to the nonsensory epithelial cells, the dark cells (DC). Like strial marginal cells, vestibular dark cells also take up $\mathrm{K}^{+}$from their basolateral membranes and release it into the endolymph at their apical membrane. A section from the lateral semicircular canal of a 2-weekold mouse was immunostained for TRPM4 (green) with DAPI counterstaining for the cell nuclei (blue). TRPM4-IR was observed in the sensory epithelium (crista ampullaris) and dark cell region; however, no TRPM4-IR was found in the transitional epithelium. B: The dark cell layer in A is enlarged. TRPM4-IR was concentrated in the luminal (apical) side of the dark cells (arrowheads). C,D: A section from the posterior semicircular canal of a 4-week-old mouse was immunostained for TRPM4 (green; C) and neurofilament H (NFH; red; D). E: Merged image of $\mathrm{C}$ and D. A mammalian vestibular organ contains two types of HCs, type I and type II. The basolateral surface of type I hair cell is enveloped by a single large afferent nerve terminal, which is called the calyx (white arrowheads in C-E). TRPM4-IR was not observed in the calyces (arrowheads in C-E). On the other hand, TRPM4-IR was observed in the more central region of some vestibular nerve fibers (white arrows in C-E). F: A nearby section was immunostained for myosin VI (red). Note that the cells that possess TRPM4-IR in C were myosin VI-immunopositive HCs (yellow arrows in C,F). Scale bars $=50 \mu \mathrm{m}$ in A,C-F; $20 \mu \mathrm{m}$ in B. red). The double labeling revealed that TRPM4-IR is also localized in a subset of the vestibular nerves' fibers (white arrows in Fig. 4C-E). The HCs of the crista ampullaris, in a section near the section in Figure 4C-E, were labeled for myosin VI to clarify the $\mathrm{HC}$ region in epithelial layer of the crista ampullaris (Fig. 4F). We observed TRPM4-IR in both types of vestibular HCs, type I and type II (Supp. Info. Fig. 3). In the vestibular ganglion located in the inner auditory meatus, weak and diffuse TRPM4-IR was barely detected in the somas of neurons (Supp. Info. Fig. 4).

\section{The Expression of TRPM4 in the Cochlea Is Markedly Upregulated at the Onset of Hearing}

To investigate changes in the distribution of TRPM4 in the cochlear duct during development, TRPM4 immunohistochemistry was performed in samples obtained from E15.5, P0, P7, 2-week-, 4-week-, 8week-, and 20-week-old mice. At E15.5, no detectable TRPM4-IR was found either in the cochlear duct (Fig. $5 \mathrm{~A}$ ) or in the SG (Fig. 5B). At P0, prominent TRPM4-
IR was already observed in the marginal cell layer of the stria vascularis (Fig. 5C). Faint TRPM4-IR was also observed in some somas in the SG at P0 (Fig. 5D). At P7, TRPM4-IR in the organ of Corti was localized exclusively at this stage in the IHCs (Fig. 5E). Moreover, weak TRPM4-IR started appearing in the neural fibers and somas of SGNs, and an additional TRPM4-IR was found in the Reissner's membrane at P7 (Fig. 5E). At 2 weeks of age, which corresponds to the onset of hearing (Shnerson and Pujol, 1981; Wangemann, 2011), intense TRPM4-IRs were present in the strial marginal cells, IHCs, Reissner's membrane, and SGNs (Fig. 5G,H). At 4 weeks of age, the distribution of TRPM4-IR in the cochlea remained the same as that found in 2-week-old specimens (Fig. 5I). However, much of the intense IR observed in the nerve fibers in SG from 2-week-old mice was diminished, and only weak TRPM4-IR was observed (Fig. 5J). There were no detectable differences in the distribution of TRPM4-IR in the cochleae from 8-week- and 20-week-old mice compared with that from 4-week-old mice (data not shown). Changes in the distribution of TRPM4-IR are summarized in Table I. 

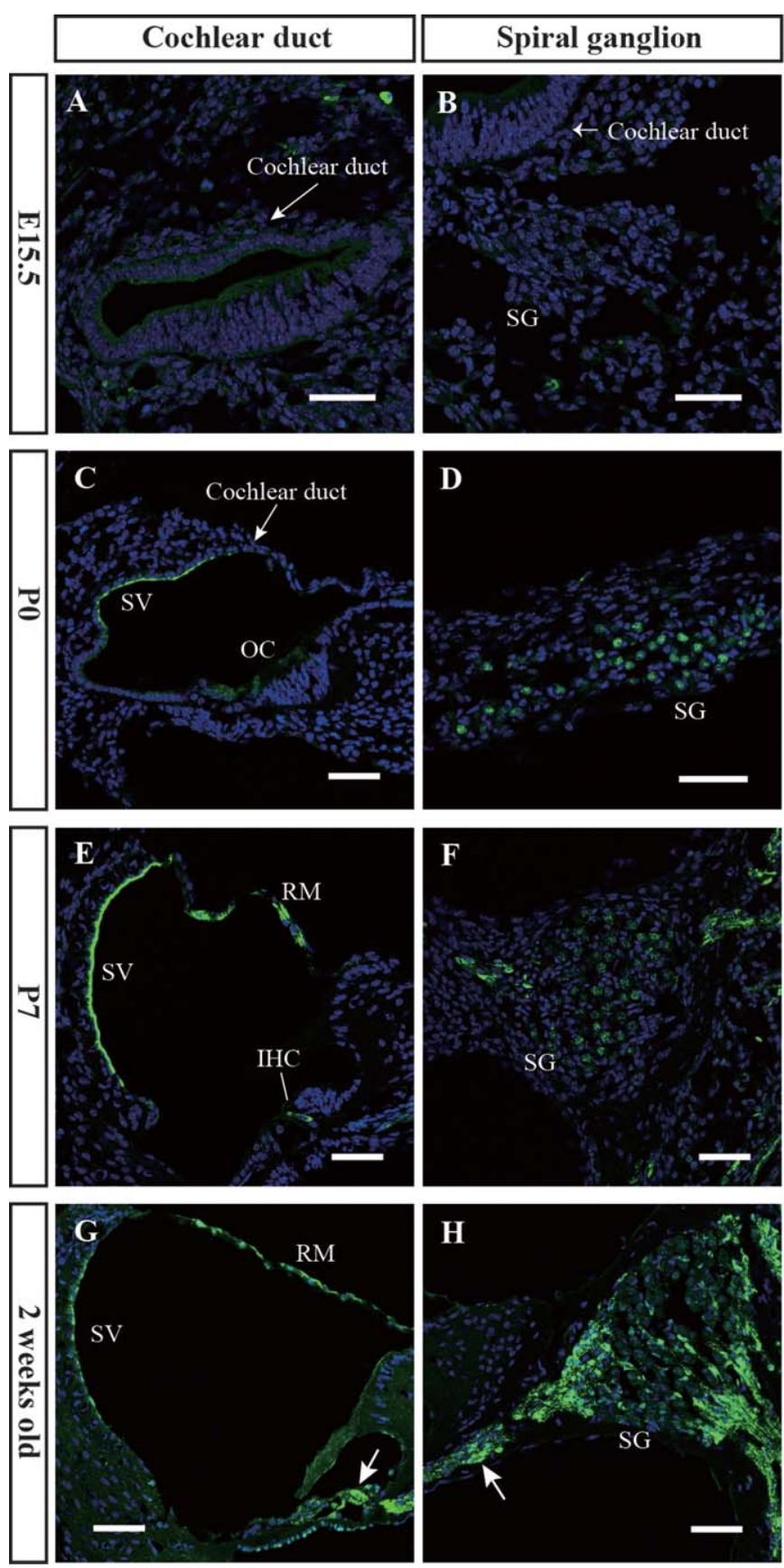

Fig. 5. The expression of TRPM4 in the cochlea is markedly upregulated at the onset of hearing. Changes in the distribution of TRPM4-IR were examined in the cochlear duct (A,C,E, G,I) and spiral ganglion (SG; $\mathrm{B}, \mathrm{D}, \mathrm{F}, \mathrm{H}, \mathrm{J})$ during development. The nuclei were counterstained by DAPI (blue). A,B: At E15.5, no TRPM4-IR was found in the cochlear duct or in the SG. C: At P0, a moderate TRPM4-IR was already observed in the stria vascularis (SV). D: At P0, a weak TRPM4-IR was observed in some SG neurons. E: At P7, a noticeable TRPM4-IR was localized to IHCs of the organ of Corti (OC). The IR in marginal cells of the SV became prominent at this stage. IR was also localized to the Reissner's membrane (RM). F: There was no noticeable difference in TRPM4-IR in the SG between P0 and P7, whereas some SG neurons were still immunoreactive to TRPM4. G: Intense TRPM4-IRs in 2week-old mice were observed in the strial marginal cells and IHCs (arrow), corresponding to the onset of hearing. H: In addition to the SG

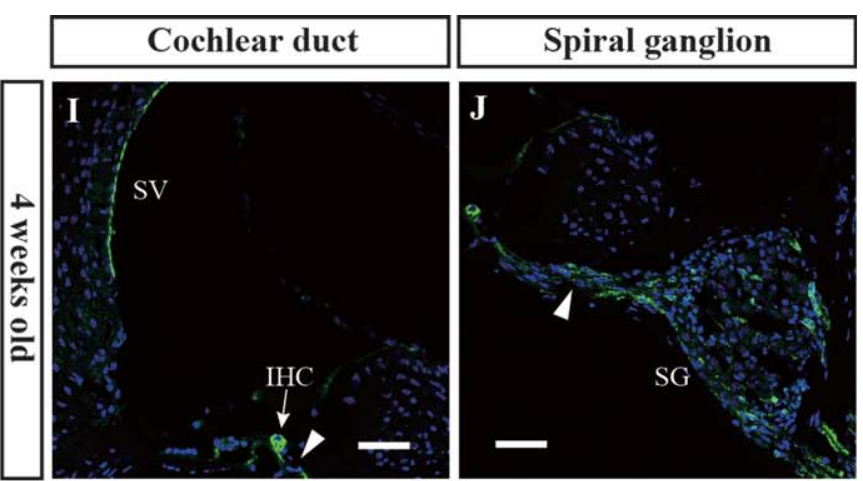

K

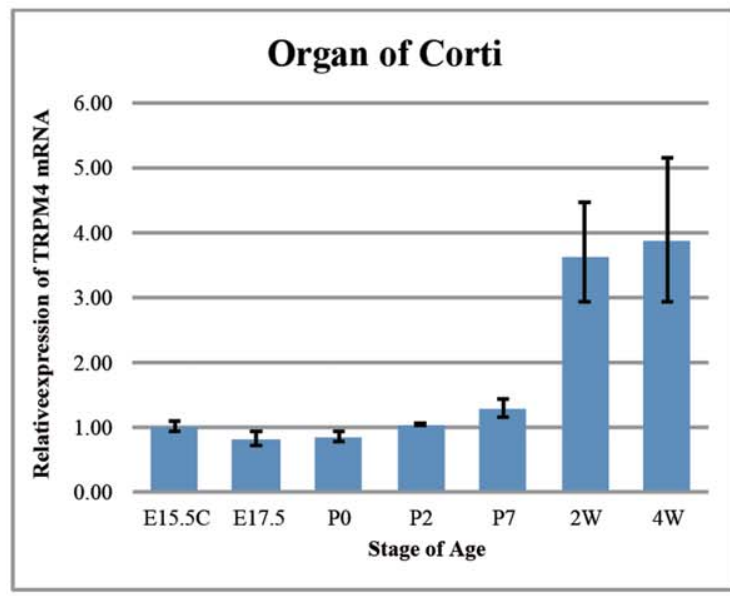

$\mathbf{L}$

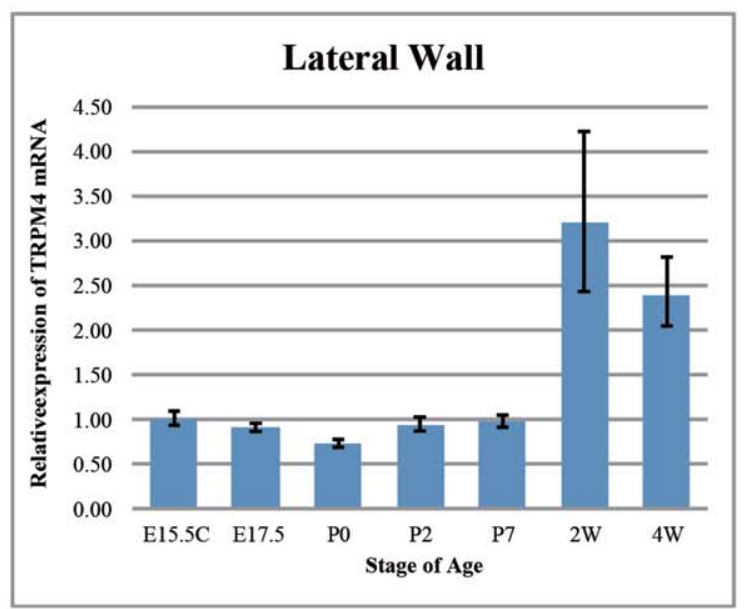

neurons, TRPM4-IR was also observed at 2 weeks of age in the nerve fibers in the SG. I: At 4 weeks of age, the distribution of TRPM4-IR in the cochlea remained the same as that observed at 2 weeks of age. J: Intense TRPM4-IR in the nerve fibers observed in SG from 2-weekold mice was diminished at 4 weeks (arrowhead). To evaluate changes in TRPM4 transcript expression in the organ of Corti and SV during development, semiquantitative RT-PCR was performed on mRNA extracted from the organ of Corti and from the lateral wall that contains the SV from mice between E15.5 and 4 weeks old. K: In the organ of Corti, the relative level of mRNA for TRPM4 surged up from P7 to 2 weeks old, concurrent with the onset of hearing. L: The relative level of mRNA for TRPM4 in the lateral wall was also markedly increased from P7 to 2 weeks of age. The error bar indicates a standard deviation of the mean in K,L. Scale bars $=50 \mu \mathrm{m}$ in A-J. 
To clarify the changes in TRPM4 expression in the cochlea during development, two tissue samples, the organ of Corti and the lateral wall containing the stria vascularis, fibrocytes, and connective tissue, were dissected from the cochlea from E17.5, P0, P2, P7, 2-week-, and 4-week-old mice. The RNA extracted from the whole cochlea was used with the sample from E15.5 mice. Semiquantitative RT-PCR was performed, and relative changes in TRPM4 transcripts were determined. In both the organ of Corti and the lateral wall, there was no obvious change in the relative level of mRNA for TRPM4 until 2 weeks of age. However, the expression surged from $\mathrm{P} 7$ to 2 weeks of age, when the onset of hearing occurs (Fig. 5K,L).

\section{DISCUSSION}

The present study demonstrates that robust TRPM4-IR is localized specifically in the soma of IHCs in the organ of Corti. This suggests that TRPM4 plays a specific role related to the function of IHCs. When sound stimuli open the mechanosensory transduction channels on the stereocillia, $\mathrm{K}^{+}$enters and depolarizes IHCs. The depolarization opens voltage-gated $\mathrm{Ca}^{2+}$ channels, and the resultant $\mathrm{Ca}^{2+}$ influx causes transmitter release from the basal end of the cell to the auditory nerve endings. Increased intracellular $\mathrm{Ca}^{2+}$ could also open TRPM4 in the soma of IHCs, leading to $\mathrm{K}^{+}$efflux and IHC repolarization. In contrast to IHCs, only diffuse and weak TRPM4-IR was observed in OHCs. The voltage-gated $\mathrm{K}^{+}$channel, KCNQ4, is abundant in OHCs at their basal membrane and is thought to mediate a major pathway for $\mathrm{K}^{+}$efflux (Kharkovets et al., 2006). In the cochlea of KCNQ4 knockout (KO) mice, OHCs gradually degenerated as hearing threshold declined by $\sim 50 \mathrm{~dB}$ over several weeks. The expression of KCNQ4 is far more limited in IHCs, and IHCs are apparently unaffected in KCNQ4 KO mice (Kharkovets et al., 2006). These results suggest the presence of an additional system in IHCs that mediates repolarization through $\mathrm{K}^{+}$efflux. Moreover, a greater expression of TRPM4 in IHCs may be needed to compensate for the relative absence of KCNQ4. At the same time, the lower expression of TRPM4 in OHCs indicates that TRPM4 is not a major player in the repolarization of $\mathrm{OHCs}$ because of the abundant presence of KCNQ4. A role for TRPM4 in repolarization of the IHCs is further suggested by TRPM4-IR in the cell body without IR on the apical membrane.

Another finding in this study was the presence of TRPM4 in the apical side of the strial marginal cells. The marginal cells transport $\mathrm{K}^{+}$from the intrastrial space into the endolymph (Kerr et al., 1982; Wangemann et al., 1995). The $\mathrm{K}^{+}$efflux into the endolymph is conducted largely by voltage-dependent $\mathrm{K}^{+}$ion channels, KCNQ1/ KCNE1 heterometric channels, which are expressed in the apical membrane of marginal cells (Sakagami et al., 1991; Marcus and Shen, 1994). Indeed, the targeted disruptions of the KCNQ1/KCNE1 gene in mice lead to deafness and show gross morphological anomalies result- ing from a drastic reduction in the volume of endolymph (Vetter et al., 1996; Casimiro et al., 2001). Although these voltage-dependent $\mathrm{K}^{+}$ion channels are essential for $\mathrm{K}^{+}$ transport, the presence of nonselective cation channels was also detected by patch-clamp electrophysiology in the apical membrane of marginal cells (Takeuchi et al., 1992; Sunose et al., 1993). The studies have demonstrated that these cation channels are activated when intracellular concentration of $\mathrm{Ca}^{2+}$ reaches $10^{-5} \mathrm{M}$. This channel has a conductance of $\sim 27 \mathrm{pS}$ for monovalent cations and does not allow $\mathrm{Ca}^{2+}$ permeation. The physiological characteristics described above correspond to those of TRPM4 and TRPM5 channels (Guinamard et al., 2010). More importantly, the cation channel was inactivated by cytoplasmic ATP (Sunose et al., 1993). Because TRPM4 is activated when internal ATP is decreased, whereas TRPM5 is not ATP sensitive (Nilius et al., 2005; Ullrich et al., 2005), these findings, together with our findings, suggest that the marginal cells possess functional TRPM4 channels. Although the exact role for TRPM4 in the apical surface of the marginal cells is currently unknown, we speculate that TRPM4 cooperates with KCNQ1/KCNE1 channels in $\mathrm{K}^{+}$transport into the endolymph.

Within the SG, TRPM4-IR was found almost exclusively in small $\beta$-III-tubulin-immuonegative type II neurons. For the inspiratory neurons, TRPM4 is known to contribute to an excitatory postsynaptic potential, which activates voltage-dependent sodium channels to induce bursting activity of the neurons (Crowder et al., 2007; Mironov, 2008). Therefore, it is possible that TRPM4 in the small, type II SG neurons might mediate the excitatory postsynaptic potentials necessary for these neurons. Electrophysiological experiments will be required to investigate this possibility.

The vestibular labyrinth that contains the sacculus, utriculus, and three semicircular canals is also filled with endolymph. When the sensory epithelium in semicircular canals is stimulated by head rotations, $\mathrm{K}^{+}$in the vestibular endolymph ( 150 mM; Wangemann, 2002) flows into HCs via the mechanotransduction channel and exits through KCNQ4 and other $\mathrm{K}^{+}$channels in the basolateral membrane (Valli et al., 1990; Kharkovets et al., 2000). Intense TRPM4-IR was found in HCs of the crista ampullaris and dark cells in the lateral semicircular canal. In the stria vascularis, dark cells constitute a monolayer lining of the endolymphatic space, similar to marginal cells, and are responsible for the production of endolymph in the semicircular canal (Nakai and Hilding, 1968). Dark cells are known to absorb the released $\mathrm{K}^{+}$ (Kikuchi et al., 1994) and transport $\mathrm{K}^{+}$back into the endolymph via KCNQ1/KCNE1 in their apical membrane (Wangemann et al., 1996; Marcus et al., 1997). Furthermore, nonselective cation current was electrophysiologically detected in the apical membrane of the vestibular dark cells (Marcus et al., 1992). This finding supports our data showing the unique presence of TRPM4 in the apical side of dark cells in the semicircular canal. Although an exact physiological role of TRPM4 in the vestibular dark cells is unknown, we speculate that TRPM4 
contributes to maintaining the high $\mathrm{K}^{+}$concentration of endolymph in the vestibule.

The present study also demonstrates changes in the distribution and expression of TRPM4 in the mouse cochlea during development. The formation of the endolymph starts shortly before birth, when the concentration of $\mathrm{K}^{+}$increases while $\mathrm{Na}^{+}$decreases. By P0, the concentrations of $\mathrm{K}^{+}$and $\mathrm{Na}^{+}$are approximately equal $(\sim 80 \mathrm{mM})$, which coincides with the onset of KCNQ1 expression in the stria vascularis (Li et al., 2013). Because TRPM4-IR was not detectable at E15.5, but was clearly observed at P0, the onset of TRPM4 expression in the stria vascularis also coincides with the onset of KCNQ1 expression and endolymph formation. In addition, qRTPCR analysis showed that TRPM4 expression was distinctly upregulated from P7 to 2 weeks old in the lateral wall of the cochlea, which coincides with the onset of hearing (P12) in mice (Shnerson and Pujol, 1981; Wangemann, 2011). These findings are in agreement with our hypothesis that TRPM4 is involved in formation of endolymph.

Another finding is that, although the onset of TRPM4 expression in the stria vascularis is in accordance with the onset of endolymph formation, TRPM4 expression in IHCs occurs shortly before the onset of hearing. An upregulation of TRPM4 transcripts from P7 to 2 weeks old would be in accordance with the timeline for development of sound perception (from P6 to P15; Wangemann, 2011) and the need for a mechanism to repolarize the IHC.

In summary, we have demonstrated that TRPM4 channels are located on the apical side of strial marginal cells and in the basolateral portion of IHCs in the cochlea of adult mice. We have also examined changes in the distribution and expression of TRPM4 during cochlear growth. The onset of TRPM4 expression in the stria vascularis coincides with the onset of endolymph formation. In contrast, the onset of TRPM4 expression in IHCs coincides with the onset of hearing. From these results, we surmise that the physiological roles of TRPM4 are related to the function of strial marginal cells and IHCs, the formation of endolymph and the sensory cell repolarization, respectively.

\section{ACKNOWLEDGMENTS}

We are grateful to Prof. Makoto Tominaga (National Institute for Physiological Sciences), Dr. Makoto Hosoya (Keio University), and Dr. Masato Fujioka (Keio University) for their critical reading of the manuscript. We profoundly thank Drs. Tomomi Ikeda and Takako Ikegami (Juntendo University) for their technical advice on realtime PCR quantification, Dr. Shinji Nakamura (Juntendo University) for his technical assistance in immunohistochemistry using the enzyme-labeled antibody method, and Dr. Tsutomu Fujimura (Juntendo University) for the synthesis of the antigen peptide and his technical advice on Western blotting. The authors have no conflicts of interest.

\section{REFERENCES}

Barclay M, Ryan AF, Housley GD. 2011. Type I vs type II spiral ganglion neurons exhibit differential survival and neuritogenesis during cochlear development. Neural Dev 6:33.

Casimiro MC, Knollmann BC, Ebert SN, Vary JC Jr, Greene AE, Franz MR, Grinberg A, Huang SP, Pfeifer K. 2001. Targeted disruption of the Kcnq1 gene produces a mouse model of Jervell and Lange-Nielsen syndrome. Proc Natl Acad Sci U S A 98:2526-2531.

Chraibi A, Van den Abbeele T, Guinamard R, Teulon J. 1994. A ubiquitous nonselective cation channel in the mouse renal tubule with variable sensitivity to calcium. Pflugers Arch 429:90-97.

Cohen-Salmon M, Ott T, Michel V, Hardelin JP, Perfettini I, Eybalin M, Wu T, Marcus DC, Wangemann P, Willecke K, Petit C. 2002. Targeted ablation of connexin26 in the inner ear epithelial gap junction network causes hearing impairment and cell death. Curr Biol 12:1106-1111.

Crowder EA, Saha MS, Pace RW, Zhang H, Prestwich GD, Del Negro CA. 2007. Phosphatidylinositol 4,5-bisphosphate regulates inspiratory burst activity in the neonatal mouse preBotzinger complex. J Physiol 582:1047-1058.

Cuajungco MP, Grimm C, Heller S. 2007. TRP channels as candidates for hearing and balance abnormalities in vertebrates. Biochim Biophys Acta 1772:1022-1027.

Drew D, Lerch M, Kunji E, Slotboom DJ, de Gier JW. 2006. Optimization of membrane protein overexpression and purification using GFP fusions. Nat Methods 3:303-313.

Earley S, Waldron BJ, Brayden JE. 2004. Critical role for transient receptor potential channel TRPM4 in myogenic constriction of cerebral arteries. Circ Res 95:922-929.

Guinamard R, Chatelier A, Demion M, Potreau D, Patri S, Rahmati M, Bois P. 2004. Functional characterization of a $\mathrm{Ca}^{2+}$-activated nonselective cation channel in human atrial cardiomyocytes. J Physiol 558:7583.

Guinamard R, Demion M, Launay P. 2010. Physiological roles of the TRPM4 channel extracted from background currents. Physiology 25: 155-164.

Guinamard R, Paulais M, Lourdel S, Teulon J. 2012. A calciumpermeable nonselective cation channel in the thick ascending limb apical membrane of the mouse kidney. Biochim Biophys Acta 1818:11351141.

Hibino H, Nin F, Tsuzuki C, Kurachi Y. 2010. How is the highly positive endocochlear potential formed? The specific architecture of the stria vascularis and the roles of the ion-transport apparatus. Pfluger Arch 459:521-533.

Hudspeth AJ. 1989. How the ear's works work. Nature 341:397-404.

Hudspeth AJ, Corey DP. 1977. Sensitivity, polarity, and conductance change in the response of vertebrate hair cells to controlled mechanical stimuli. Proc Natl Acad Sci U S A 74:2407-2411.

Kerr TP, Ross MD, Ernst SA. 1982. Cellular localization of $\mathrm{Na}^{+}, \mathrm{K}^{+}-$ ATPase in the mammalian cochlear duct: significance for cochlear fluid balance. Am J Otolaryngol 3:332-338.

Kharkovets T, Hardelin JP, Safieddine S, Schweizer M, El-Amraoui A, Petit C, Jentsch TJ. 2000. KCNQ4, a $\mathrm{K}^{+}$channel mutated in a form of dominant deafness, is expressed in the inner ear and the central auditory pathway. Proc Natl Acad Sci U S A 97:4333-4338.

Kharkovets T, Dedek K, Maier H, Schweizer M, Khimich D, Nouvian R, Vardanyan V, Leuwer R, Moser T, Jentsch TJ. 2006. Mice with altered KCNQ4 $\mathrm{K}^{+}$channels implicate sensory outer hair cells in human progressive deafness. EMBO J 25:642-652.

Kikuchi T, Adams JC, Paul DL, Kimura RS. 1994. Gap junction systems in the rat vestibular labyrinth: immunohistochemical and ultrastructural analysis. Acta Otolaryngol 114:520-528.

Launay P, Fleig A, Perraud AL, Scharenberg AM, Penner R, Kinet JP. 2002. TRPM4 is a $\mathrm{Ca}^{2+}$-activated nonselective cation channel mediating cell membrane depolarization. Cell 109:397-407. 
Li X, Zhou F, Marcus DC, Wangemann P. 2013. Endolymphatic $\mathrm{Na}^{+}$ and $\mathrm{K}^{+}$concentrations during cochlear growth and enlargement in mice lacking Slc26a4/pendrin. PloS One 8:e65977.

Marcus DC, Shen Z. 1994. Slowly activating voltage-dependent $\mathrm{K}^{+}$conductance is apical pathway for $\mathrm{K}^{+}$secretion in vestibular dark cells. Am J Physiol 267:C857-C864.

Marcus DC, Takeuchi S, Wangemann P. 1992. $\mathrm{Ca}^{2+}$-activated nonselective cation channel in apical membrane of vestibular dark cells. Am J Physiol 262:C1423-C1429.

Marcus DC, Sunose H, Liu J, Shen Z, Scofield MA. 1997. P2U purinergic receptor inhibits apical IsK/KvLQT1 channel via protein kinase $\mathrm{C}$ in vestibular dark cells. Am J Physiol 273:C2022-C2029.

Mironov SL. 2008. Metabotropic glutamate receptors activate dendritic calcium waves and TRPM channels which drive rhythmic respiratory patterns in mice. J Physiol 586:2277-2291.

Montell C, Rubin GM. 1989. Molecular characterization of the Drosophila trp locus: a putative integral membrane protein required for phototransduction. Neuron 2:1313-1323.

Nakai Y, Hilding D. 1968. Vestibular endolymph-producing epithelium. Electron microscopic study of the development and histochemistry of the dark cells of the crista ampullaris. Acta Otolaryngol 66:120-128.

Nilius B, Prenen J, Janssens A, Voets T, Droogmans G. 2004. Decavanadate modulates gating of TRPM4 cation channels. J Physiol 560:753765 .

Nilius B, Prenen J, Tang J, Wang C, Owsianik G, Janssens A, Voets T, Zhu MX. 2005. Regulation of the $\mathrm{Ca}^{2+}$ sensitivity of the nonselective cation channel TRPM4. J Biol Chem 280:6423-6433.

Nin F, Hibino H, Doi K, Suzuki T, Hisa Y, Kurachi Y. 2008. The endocochlear potential depends on two $\mathrm{K}^{+}$diffusion potentials and an electrical barrier in the stria vascularis of the inner ear. Proc Natl Acad Sci U S A 105:1751-1756.

Roux I, Hosie S, Johnson SL, Bahloul A, Cayet N, Nouaille S, Kros CJ, Petit C, Safieddine S. 2009. Myosin VI is required for the proper maturation and function of inner hair cell ribbon synapses. Hum Mol Gen 18:4615-4628.

Sakagami M, Fukazawa K, Matsunaga T, Fujita H, Mori N, Takumi T, Ohkubo H, Nakanishi S. 1991. Cellular localization of rat Isk protein in the stria vascularis by immunohistochemical observation. Hearing Res 56:168-172.

Shnerson A, Pujol R. 1981. Age-related changes in the C57BL/6J mouse cochlea. I. Physiological findings. Brain Res 254:65-75.

Soule HD, Vazguez J, Long A, Albert S, Brennan M. 1973. A human cell line from a pleural effusion derived from a breast carcinoma. J Natl Cancer Inst 51:1409-1416.

Sunose H, Ikeda K, Saito Y, Nishiyama A, Takasaka T. 1993. Nonselective cation and $\mathrm{Cl}$ channels in luminal membrane of the marginal cell. Am J Physiol 265:C72-C78.
Takeuchi S, Marcus DC, Wangemann P. 1992. $\mathrm{Ca}^{2+}$-activated nonselective cation, maxi $\mathrm{K}^{+}$and $\mathrm{Cl}^{-}$channels in apical membrane of marginal cells of stria vascularis. Hearing Res 61:86-96.

Takumida M, Ishibashi T, Hamamoto T, Hirakawa K, Anniko M. 2009. Expression of transient receptor potential channel melastin 1-8 and TRPA1 (ankyrin) in mouse inner ear. Acta Otolaryngol 129:10501060.

Teruyama R, Sakuraba M, Kurotaki H, Armstrong WE. 2011. Transient receptor potential channel $\mathrm{m} 4$ and $\mathrm{m} 5$ in magnocellular cells in rat supraoptic and paraventricular nuclei. J Neuroendocrinol 23:12041213.

Tesfai Y, Brereton HM, Barritt GJ. 2001. A diacylglycerol-activated $\mathrm{Ca}^{2+}$ channel in PC12 cells (an adrenal chromaffin cell line) correlates with expression of the TRP-6 (transient receptor potential) protein. Biochem J 358:717-726.

Ullrich ND, Voets T, Prenen J, Vennekens R, Talavera K, Droogmans G, Nilius B. 2005. Comparison of functional properties of the $\mathrm{Ca}^{2+}$ activated cation channels TRPM4 and TRPM5 from mice. Cell Calcium 37:267-278.

Valli P, Zucca G, Botta L. 1990. Perilymphatic potassium changes and potassium homeostasis in isolated semicircular canals of the frog. J Physiol 430:585-594.

Vetter DE, Mann JR, Wangemann P, Liu J, McLaughlin KJ, Lesage F, Marcus DC, Lazdunski M, Heinemann SF, Barhanin J. 1996. Inner ear defects induced by null mutation of the isk gene. Neuron 17:12511264.

Von Bekesy G. 1952. Resting potentials inside the cochlear partition of the guinea pig. Nature 169:241-242.

Wangemann P. 2002. $\mathrm{K}^{+}$cycling and its regulation in the cochlea and the vestibular labyrinth. Audiol Neurootol 7:199-205.

Wangemann P. 2011. The role of pendrin in the development of the murine inner ear. Cell Physiol Biochem 28:527-534.

Wangemann P, Liu J, Marcus DC. 1995. Ion transport mechanisms responsible for $\mathrm{K}^{+}$secretion and the transepithelial voltage across marginal cells of stria vascularis in vitro. Hearing Res 84:19-29.

Wangemann P, Shen Z, Liu J. 1996. $\mathrm{K}^{+}$-induced stimulation of $\mathrm{K}^{+}$ secretion involves activation of the IsK channel in vestibular dark cells. Hearing Res 100:201-210.

Zdebik AA, Wangemann P, Jentsch TJ. 2009. Potassium ion movement in the inner ear: insights from genetic disease and mouse models. Physiology 24:307-316.

Zhang Z, Zhao Z, Margolskee R, Liman E. 2007. The transduction channel TRPM5 is gated by intracellular calcium in taste cells. J Neurosci 27:5777-5786. 